\title{
Association between anxiety and depression with chronic periodontitis
}

\author{
Sajeev Shrestha ${ }^{1}$, Shivalal Sharma ${ }^{1}$, Nidesh Sapkota ${ }^{2}$, Dhirendra K Giri ${ }^{3}$, Dharanidhar Baral ${ }^{4}$ \\ ${ }^{1}$ Department of Periodontology and Oral Implantology, ${ }^{2}$ Department of Psychiatry, ${ }^{4}$ School of Public Health \\ and Community Medicine, BP Koirala Institute of Health Sciences, Dharan, Nepal, ${ }^{3}$ Department of \\ Periodontology, Nobel Medical College, Biratnagar
}

\section{Correspondence}

Dr. Sajeev Shrestha

Assistant Professor, Department of

Periodontology and Oral

Implantology, BP Koirala Institute

of Health Sciences, Dharan, Nepal

\section{Email:}

sajeevshrestha@gmail.com

DOI: http://dx.doi.org/10.3126/ jcmsn.v13i2.17712

Article received: $18^{\text {th }}$ Dec 2016 Article accepted: $14^{\text {th }}$ Feb 2017

\begin{abstract}
Background \& Objectives: It is thought that chronic stress negatively affects immune response efficacy which in turn cause an imbalance between host and parasite leading to periodontal breakdown. The study aims to investigate the association between anxiety and depression with chronic periodontitis. Materials \& Methods: This was a cross sectional study comprising of 350 individuals of both sexes, above 25 years of age. The study population was divided into two groups. Group 2 consisted of those subjects with clinical attachment loss of $\geq 3$ $\mathrm{mm}$ in at least $30 \%$ of site examined, and the samples that did not satisfy the above criteria were categorized into Group 1. Group 1 included 184 individuals while group 2 had 166 subjects. Clinical examinations were performed by a single examiner. Psychological instrument used was Hospital anxiety and depression scale (HADS). Chi square and student $t$ test were performed to compare between the two groups. Results: The mean depression scores in Group 1 and Group 2 were $6.64 \pm 2.58$ and $7.90 \pm 2.86$, respectively while the mean anxiety scores of Group 1 and Group 2 were $7.76 \pm 3.12$ and $9.07 \pm 3.08$, respectively $(p<001)$. Conclusion: Within the limits of this study it is possible to conclude that there was significant association between periodontitis and anxiety, and depression

Key words: Anxiety; depression; clinical attachment loss; periodontitis
\end{abstract}

Citation: Shrestha S, Sharma S, Sapkota N, Giri DK, Baral D. Association between anxiety and depression with chronic periodontitis. JCMS Nepal. 2017;13(2):268-74.

\section{INTRODUCTION}

Chronic periodontitis has been defined as "an infectious disease resulting in inflammation within the supporting tissues of the teeth, progressive attachment loss and bone loss". ${ }^{1}$ It is initiated by bacterial plaque, the pathogenesis of the disease is primarily affected by local and systemic conditions that affect the resistance of the host to infecting periodontal organisms ${ }^{2,3}$ as well as by host defense mechanisms. ${ }^{1}$ Psychosocial factors like stress, anxiety and depression are emerging as risk element in various systemic diseases including chronic periodontitis. Many studies have found relationship between anxiety, depression and chronic periodontitis. ${ }^{4,5}$

Stress increases the prevalence of periodontitis by two ways. Firstly, stress can result in the deregulation of immune system, mediated primarily through the hypothalamic-pituitary-adrenal and sympathetic-adrenal-medullary axes predisposing periodontitis. Secondly stressed people adopt health impairing behaviors such as poor oral hygiene maintenance, increased consumption of cigarettes and alcohol, and disturb sleeping patterns. Other behaviors potentially harmful to the periodontium are bruxism, anxiety induced forgetfulness and difficulty in concentration. ${ }^{6}$

Although there is a plausible biological hypothesis that could link depression and anxiety in the development and progression of periodontal disease results from observational studies are conflicting and some studies even found no association between 
stress and periodontal disease. ${ }^{7,8}$ Therefore, the present study aims to evaluate the relationship of anxiety and depression with severity of periodontitis among patients reporting to the Outpatient Department of a tertiary care hospital of eastern Nepal.

\section{MATERIALS AND METHODS}

This was a comparative cross-sectional study conducted at College of Dental Surgery, BPKIHS, and Dharan, Nepal. The study population was patients attending OPD of Department of Periodontology and Oral Implantology who fulfilled the inclusion criteria. The study samples were selected according to purposive sampling technique and the total number of subjects was 350 . The study population was divided into two groups; Group 2/(Periodontitis group) consisted of sample having clinical attachment (CA) loss of $\geq 3 \mathrm{~mm}$ in at least $30 \%$ site examined, and the samples that did not satisfy the above criteria were categorized into Group 1. The patients who were willing to enroll in the study were included in the study only after signing a written informed consent. They were assured that the data given by them would be kept confidential. Their demographic and socioeconomic data included age, sex, marital status, religion, residence, educational status, occupation, smoking habit and tooth brushing frequency.

\section{Inclusion criteria}

- Patients of either sex with age above 25 .

- Patient with at least 20 natural teeth within both jaws.

\section{Exclusion criteria}

- Periodontal therapy within past three months (scaling, root planing and polishing, periodontal surgery etc.)

- Patient requiring antibiotic prophylaxis (Rheumatic heart disease),

- Diagnosed case of diabetes mellitus, HIV infection, renal diseases

- Patients taking any medications for any psychiatric diseases.

- Patients under medications for seizures (anticonvulsant drugs), hypertension (calcium channel blockers) or under immunosuppressant therapy.

- Patient on long term NSAIDs therapy for musculoskeletal problem

- Patients who had taken antibiotics for any reason in the past three months

- Pregnant and lactating mother
- Malignancies

\section{Clinical examination}

The periodontal examinations included dental plaque, gingival condition, probing pocket depth and clinical attachment loss. . The presence of plaque and gingival condition were recorded using the Plaque index ( PI ) and Gingival index ( GI ). ${ }^{9}$ The clinical periodontal examinations were carried out manually using UNC-15 probe (Hu-Friedy, IL, USA). The CA loss and probing pocket depth (PD) were measured in four sites (mesial-facial, midfacial, distal-facial and palatal/lingual) per tooth. The PD was measure of distance from the gingival margin to the base of gingival sulcus or periodontal pocket. The CA loss was the distance from the cemento-enamel junction (CEJ) to the base of the gingival sulcus or periodontal pocket. After clinical examination, the patients were given self-reporting questionnaires to collect the data regarding psychosocial factor like depression and anxiety. The psychometric instrument which was used was Hospital Anxiety and Depression Scale (HADS). ${ }^{10}$ The hospital Anxiety and Depression Scale (HADS) had been used in several languages to assess anxiety and depression in general hospital patients with good results. The HADS has been translated and widely used in more than 25 countries since its development. For our study too, the HADS was translated into Nepalese language. The HADS was a self-reported rating scale of 14 items on a 4-point Linker scale (range 0 to 3 ). It was designed to measure anxiety and depression (7 items for each subscale). If the total sub score were $\leq 7$ for each scale of depression /anxiety; then, no depression/anxiety were present. If the total sub score were 8 to 10 ; then, doubtful anxiety/ depression were present. If the total sub score were $\geq 11$; then, definite depression/anxiety were present. The translated version of HADS with result scores were retranslated back into English for analysis. The study was carried out after approval by the Institutional Review Committee of BPKIHS.

\section{Sample size calculation and Statistical Analysis}

This study considered $95 \%$ confidence interval (CI) and $80 \%$ power for sample size estimation. The sample size was calculated based on previous study by Vettore et $\mathrm{al}^{11}$ who found that $27 \%$ prevalence of anxiety and stress in Group 1 i.e. in mild to healthy periodontitis cases and odds ratio $(\mathrm{OR})=1.8 \approx 2$. Collected data were entered in Microsoft Excel 2007 and were analyzed in Statistical package for social science (SPSS) version 11.0. For inferential 
statistics, Chi square, student t-test and were applied to find out the significant difference between dependent and independent variables at $95 \%$ confidence interval ( CI ) where $\mathrm{p}=0.05$.

\section{RESULTS}

The study was conducted between August 2012 and July 2013. The socio demographic characteristics, and smoking status and brushing frequency of the study population are summarized in table 1 and 2, respectively. Likewise the periodontal parameters of Group 1 and Group 2 are shown in table 3.

The anxiety and depression status in two different categories of periodontitis were depicted in figure 1 and figure 2 , respectively.

\section{DISCUSSION}

Periodontal diseases are opportunistic infections caused by specific periopathogens and their metabolic products. Epidemiological studies indicate several so-called risk factors and risk indicators that may be closely related to the emergence and progression of periodontitis. An increasing number of studies have shown that psychological stress or other psychosomatic conditions lead to immunological changes and/or behavior-mediated effects which may have direct modulating effects on the immune system of the body. ${ }^{12}$

In our study, we use the definition of "periodontitis" as having clinical attachment loss of 3 or more than $3 \mathrm{~mm}$ in at least $30 \%$ of examined site and were kept in Group 2. The subjects who did not fit in this category were included in Group 1. The mean age of subjects of Group 1 and Periodontitis group were $31.56 \pm 6.47$ and $50.38 \pm$ 10.27 years, respectively which was statistically significant $(p<0.001)$. The reason of older sample having periodontitis could be probably due to the cumulative nature of the loss of periodontal support reflecting the length of exposure to the etiologic factors. ${ }^{13}$ These results were in consistent with numerous previous studies that had reported higher prevalence and severity of periodontal disease with increasing age. ${ }^{14,15}$ In our study, gender was not found as risk indicator of periodontitis as $\mathrm{p}=0.071$

Table 1: Socio demographic characteristics of two different groups of the periodontal patients

\begin{tabular}{|c|c|c|c|c|c|}
\hline \multirow{2}{*}{\multicolumn{2}{|c|}{ Characteristics }} & \multicolumn{2}{|c|}{ Groups } & \multirow{2}{*}{ p value } & \multirow{2}{*}{ Remarks } \\
\hline & & Group 1 & Group 2 & & \\
\hline \multirow{4}{*}{ Age group in years } & $25-34$ & 128 & 10 & \multirow{4}{*}{-} & \multirow{4}{*}{-} \\
\hline & $35-44$ & 45 & 37 & & \\
\hline & $45-54$ & 5 & 60 & & \\
\hline & $\geq 55$ & 6 & 59 & & \\
\hline \multicolumn{2}{|c|}{ Mean age in years $\pm \mathrm{SD}$} & $31.84 \pm 7.09$ & $50.38 \pm 10.27$ & $<0.001$ & $\mathrm{~S}^{\#}$ \\
\hline \multirow{2}{*}{ Gender } & Male & 100 & 106 & \multirow{2}{*}{0.071} & \multirow{2}{*}{ NS* } \\
\hline & Female & 84 & 60 & & \\
\hline \multirow{2}{*}{ Marital status } & Married & 140 & 160 & \multirow{2}{*}{$<0.001$} & \multirow{2}{*}{$\mathrm{S}^{*}$} \\
\hline & Unmarried & 44 & 6 & & \\
\hline \multirow{4}{*}{ Religion } & Hindu & 121 & 128 & \multirow{4}{*}{0.019} & \multirow{4}{*}{$\mathrm{S}^{*}$} \\
\hline & Buddhist & 15 & 10 & & \\
\hline & Kirant & 42 & 23 & & \\
\hline & Others & 6 & 5 & & \\
\hline \multirow{2}{*}{ Residence } & Rural & 23 & 36 & \multirow{2}{*}{0.022} & \multirow{2}{*}{$\mathrm{S}^{*}$} \\
\hline & Urban & 161 & 130 & & \\
\hline \multirow{3}{*}{ Education status } & Up to Class 5 & 16 & 60 & \multirow{3}{*}{$<0.001$} & \multirow{3}{*}{$\mathrm{S}^{*}$} \\
\hline & Class 5- 12 & 91 & 77 & & \\
\hline & Above 12 & 77 & 29 & & \\
\hline
\end{tabular}

*= chi square test, $\#=$ student $\mathrm{t}$ test 
Table 2: Personal behaviors of two different groups of the periodontal patients

\begin{tabular}{|c|c|c|c|c|c|}
\hline \multirow{2}{*}{ Characteristics } & & \multicolumn{2}{|l|}{ Groups } & \multirow{2}{*}{ p value } & \multirow{2}{*}{ Remarks } \\
\hline & & Group 1 & Group 2 & & \\
\hline \multirow{2}{*}{ Smoking } & Yes & 35 & 74 & \multirow{2}{*}{$<0.001$} & \multirow{2}{*}{$\mathrm{S}$} \\
\hline & No & 149 & 92 & & \\
\hline \multirow{2}{*}{ Brushing frequency } & Once & 151 & 145 & \multirow{2}{*}{0.172} & \multirow{2}{*}{ NS } \\
\hline & Twice & 33 & 21 & & \\
\hline Total & & 184 & 166 & & \\
\hline
\end{tabular}

Table 3: Periodontal parameters of two different groups of the periodontal patients

\begin{tabular}{|c|c|c|c|c|c|}
\hline \multirow{2}{*}{\multicolumn{2}{|c|}{ Characteristics }} & \multicolumn{2}{|l|}{ Groups } & \multirow{2}{*}{ p value } & \multirow{2}{*}{ Remarks } \\
\hline & & Group 1 & Group 2 & & \\
\hline \multirow{3}{*}{ Plaque index } & Good & 28 & 6 & \multirow{3}{*}{-} & \multirow{3}{*}{-} \\
\hline & Fair & 151 & 121 & & \\
\hline & Poor & 5 & 39 & & \\
\hline \multicolumn{2}{|c|}{ Plaque index $($ Mean \pm SD) } & $1.27 \pm 0.29$ & $1.73 \pm 0.35$ & $<0.001$ & $\mathrm{~S}^{\#}$ \\
\hline \multirow{3}{*}{ Gingival index } & Mild gingivitis & 23 & 6 & \multirow{3}{*}{-} & \multirow{3}{*}{-} \\
\hline & Moderate gingivitis & 155 & 135 & & \\
\hline & Severe gingivitis & 6 & 25 & & \\
\hline \multicolumn{2}{|c|}{ Gingival index $($ Mean \pm SD) } & $1.27 \pm 0.27$ & $1.68 \pm 0.37$ & $<0.001$ & $\mathrm{~S}^{\#}$ \\
\hline \multicolumn{2}{|c|}{ Probing pocket depth (Mean \pm SD) } & $2.26 \pm 0.25$ & $3.05 \pm 0.38$ & $<0.001$ & $\mathrm{~S}^{\#}$ \\
\hline \multicolumn{2}{|l|}{ Total } & 184 & 166 & & \\
\hline \multicolumn{2}{|c|}{ Median Clinical attachment loss } & 0.526 & 2.116 & $<0.001$ & $\mathrm{~S}^{\#}$ \\
\hline \multicolumn{2}{|c|}{ Inter quartile range } & $0.405-0.642$ & $\begin{array}{l}1.602- \\
3.013\end{array}$ & - & - \\
\hline \multicolumn{2}{|l|}{ Total } & $126^{\$}$ & 166 & - & - \\
\hline
\end{tabular}

\# = student $\mathrm{t}$ test, $\$=$ Out of 184 subjects in group 1, 58 did not have clinical attachment loss. Therefore, they were excluded and the remaining subject in group 1 is equal to 126.

but was consistent to various previous studies done by Solis et al, ${ }^{16}$ and Vettori et al. ${ }^{11}$ The reason for this inconsistence might be that the total number of female subjects in our study was less as compared to male (206 male and 144 female). In the present study, disease was more common in married subjects which was in consistent with the study of Marcenes and Sheiham. ${ }^{17}$ The reason might be that work-related mental demand is more married persons. In our study, the prevalence of periodontitis was more common in Hindu followed by Buddhist while the prevalence of periodontitis was less in Kirants. The difference of disease status based upon religious community was statistically significant as $p=0.019$. In our study, people from rural area had higher prevalence of disease in comparison to those living in urban areas. This difference between two groups was statistically significant as $p=0.022$. This might be due to the fact that people from rural areas are usually less aware of importance of oral health and hygiene and also oral health facilities are limited to urban areas. Our study also showed that with the increase in the level of education, the prevalence of periodontitis decreases which was in consistent with the study done by Castro GDC. ${ }^{7}$

The present study also revealed that smoking was significantly associated with periodontitis $(p<001)$. Tobacco nicotine and its byproducts have a vasoconstrictive effect, not only on peripheral circulation but also on coronary, placental, and gingival blood vessels as well. ${ }^{18}$ In addition, 
Anxiety status of two different groups of the population

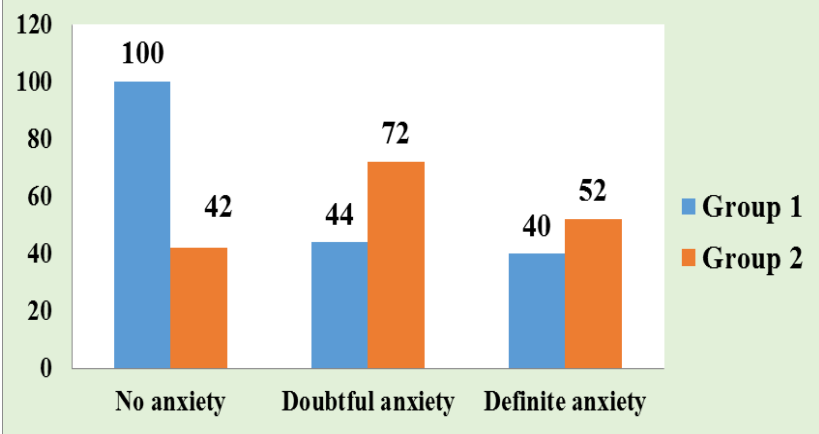

Figure 1: Anxiety status of two different groups of the population

\section{Depression status of two different groups of the population}

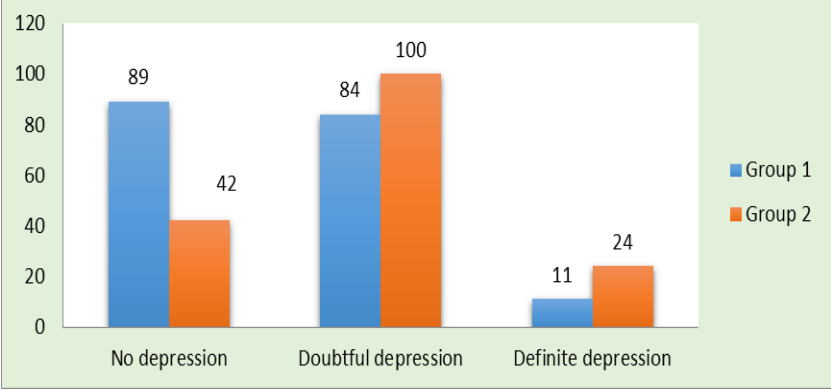

Figure 2: Depression status of two different groups of the population

smoking may reduce the functional activity of leukocytes and macrophages in saliva and crevicular fluid, as well as decreasing chemotaxis and phagocytosis of blood and tissue polymorphonuclear leukocytes, thereby likely depressing phagocyte-mediated protective responses to periodontal pathogens. ${ }^{19}$

The study also revealed that both plaque and gingival index scores were higher in the Periodontitis group compared to Group 1. The result of our study was in consistent with previous population-based study that had shown a positive correlation between plaque and periodontal disease. ${ }^{13}$ As in various other studies, the difference in the probing depth Group 1 and Group 2 were statistically significant $(\mathrm{p}<0.001){ }^{7,11,20}$

Stress is a complex term covering many variables and processes, such as number of major life events during the previous year, total and average perceived stress in relation to these events, daily hassles and anticipated future stressors. In addition, stress can involve depression and anxiety as reactions to stressors impinging on individuals. ${ }^{21}$ In the present study, we selected Hospital Anxiety and Depression scales for assessment of level of anxiety and depression. In our study the mean depression scores in Group 1 and Periodontitis group were $6.64 \pm 2.58$ and $7.90 \pm 2.86$, respectively. The difference was statistically significant between the groups. Likewise, the mean anxiety scores of Group 1 and Periodontitis group were $7.76 \pm 3.12$ and $9.07 \pm 3.08$, respectively which were also statistically significant between the two groups ( $\mathrm{p}<$ 0.001 ). HADS was also used by Monterio da Silva to evaluate the association between psychosocial factors and periodontitis. ${ }^{21}$ In their study, 50 rapidly progressive periodontitis (RPP), 50 routine chronic adult periodontitis (RCAP) and 50 patients without significant periodontal destruction (controls) were selected to assess the psychosocial factors. The RPP group presented significantly increased depression and loneliness compared to the RCAP and control groups.

Cross sectional studies with large number of population sample revealed significant association between psychosocial factors and periodontitis., ${ }^{4,5}$,

22. Genco et al found that stress, revealed as financial strain, and depression were associated with greater levels of clinical attachment loss or higher levels of alveolar bone loss, ${ }^{2}$ independently measured but correlated measures of destructive periodontal disease. ${ }^{4}$

The result of our study was in consistent to the case control studies done by Moss et al, ${ }^{20}$ Vettore et al, ${ }^{11}$ and Saletu et al. ${ }^{23}$ The differences were in the definition of periodontitis criteria. Moss used the criteria given by Machtei et $\mathrm{al}^{24}$ for established periodontitis. The baseline criteria for established periodontitis were as follows: two or more interproximal sites from different teeth with clinical attachment level of $6 \mathrm{~mm}$ or greater and at least one additional site with a pocket depth of $5 \mathrm{~mm}$ or greater. Other differences were the use of different psychometric instrument scale for assessment of level of depression and anxiety such as Vettore et $\mathrm{al}^{11}$ used Stress Symptom Inventory (SSI), StateTrait Anxiety Scale (STAI) and Social Readjustment Rating Scale (SRRS) while Saletu et $\mathrm{al}^{23}$ used Zung Self Rating Depression Scale (SDS) and Zung Self Rating Anxiety Scale (SAS).

The finding of this study was similar to the cross section study conducted by Solis et al16 who did not find any association between depression, hopelessness, psychiatric symptoms and established periodontitis. The reason might be that the mean Beck Depression Inventory (BDI) and State Trait Anxiety Inventory (STAI) scores were compatible 
with normality if compared with populations with a clinical diagnosis of depressive and anxiety disorders. Similarly, the case- control study conducted by Castro et $\mathrm{al}^{7}$ also did not find significant association between periodontitis and psychosocial factors. The reason might be that individual characteristics, such as social support and ways of coping, may affect the way subjects deal with stressful situations and how they respond to periodontal treatment. ${ }^{25}$

Currently there are two proposed models that evaluate the role of psychosocial stress and coping behaviors in periodontal disease. The first model focuses on both the hypothalamic-pituitary-adrenal (HPA) and sympathetic- adrenal medullary axes (SAM axes) while the second model centers on the behavioral changes that might lead to immunosuppression. ${ }^{6}$ According to the first major pathway that focuses on HPA axis, in response to a variety of stressful stimuli, following sequences of events are initiated. First activation of hypothalamic -pituitary-adrenal axis by stress, results in release of an increased concentration of corticotrophin releasing hormone from the hypothalamus then corticotrophin releasing hormone in turn acts on the anterior pituitary, resulting in the release of $\mathrm{ACTH}$ (adrenocorticotropic hormone). The ACTH then acts on the adrenal cortex and cause the production and release of glucocorticoid hormones (predominantly cortisol) into the blood circulation. The glucocorticoids then produce myriads of effects throughout the body, such as suppressing the inflammatory response, modifying cytokine profiles, elevating blood glucose levels and altering levels of certain growth factors. . Increase level of glucocorticoid may provoke an inappropriate $\mathrm{T}$ helper 2 cell response. The second major pathway to be activated is the sympathetic nervous system e.g. 'flight' and 'fight' response to potentially harmful stimuli. Catecholamine, released during stress, results in the development of hyperglycemia by stimulating glucose production, interfering with the tissue disposal of glucose and regulating immune cell activities. ${ }^{26,27}$

\section{CONCLUSION}

The level and prevalence of anxiety and depression were higher in more severe case of periodontitis compared to less severe case of periodontitis. Within the limit our study, there was significant association between anxiety and depression with chronic periodontitis. Further prospective studies using biochemical markers would be reliable to clarify the role of psychosocial factors and their mechanisms of action in the periodontal tissues.

\section{ACKNOWLEDGEMENTS}

The authors thank Dr Bikash Sah, Assistant Professor, of Forensic Medicine, BPKIHS for supporting in the preparation of the manuscript.

\section{REFERENCES}

1. Flemmig TF. Periodontitis. Ann Periodontol. 1999;4(1):3237. https://doi.org/10.1902/annals.

2. Page RC, Kornman KS. The pathogenesis of human periodontitis: an introduction. Periodontol 2000. 1997;14:911 .

3. Genco RJ. Current view of risk factors for periodontal diseases. J Periodontol. 1996;67(10 Suppl):1041-1049. https://doi.org/10.1902/jop.1996.67.10.1041

4. Genco RJ, Ho AW, Grossi SG, Dunford RG, Tedesco LA. Relationship of stress, distress and inadequate coping behaviors to periodontal disease. J Periodontol. 1999;70 (7):711-723. https://doi.org/10.1902/jop.1999.70.1.100.

5. Ng SKS, Leung WK. A community study on the relationship of dental anxiety with oral health status and oral health-related quality of life. Community Dent Oral Epidemiol. 2008;36(4):347-356.

6. Boyapati L, Wang H-L. The role of stress in periodontal disease and wound healing. Periodontol 2000. 2007:44:195 -210. https://doi.org/10.1111/j.1600-0757.2007.00211.x.

7. Castro GDC, Oppermann R V., HAAS AN, Winter R, Alchieri JC. Association between psychosocial factors and periodontitis: a case-control study. J Clin Periodontol. 2006;33(2):109-114.https://doi.org/10.1111/j.1600051X.2005.00878.x.

8. Persson GR, Persson RE, MacEntee CI, Wyatt CCII, Hollender LG, Kiyak HA. Periodontitis and perceived risk for periodontitis in elders with evidence of depression. $\mathrm{J}$ Clin Periodontol. 2003;30(8):691-696. https:// doi.org/10.1034/j.1600-051X.2003.00360.x. PMID: 12887337

9. Löe H. The Gingival Index, the Plaque Index and the Retention Index Systems. J Periodontol. 1967;38 (6):Suppl:610-6. https://doi.org/10.1902/jop.1967.38.6.610.

10. Zigmond AS, Snaith RP. The hospital anxiety and depression scale. Acta Psychiatr Scand. 1983;67(6):361370. https://doi.org/10.1111/j.1600-0447.1983.tb09716.x.

11. Vettore M V, Leão ATT, Monteiro Da Silva AM, Quintanilha RS, Lamarca GA. The relationship of stress and anxiety with chronic periodontitis. J Clin Periodontol. 2003;30(5):394-402. https://doi.org/10.1034/j.1600051X.2003.10271.x. PMID: 12716330

12. Breivik T, Thrane PS, Murison R, Gjermo P. Emotional stress effects on immunity, gingivitis and periodontitis. Eur J Oral Sci. 1996;104(4 ( Pt 1)):327-334. https:// doi.org/10.1111/j.1600-0722.1996.tb00087.x. PMID: 8930578.

13. Löe H, Anerud A, Boysen H, Smith M. The Natural History of Periodontal Disease in Man: The Rate of Periodontal Destruction Before 40 Years of Age. J Periodontol. 1978;49(12):607-620. https://doi.org/10.1902/ jop.1978.49.12.607.

14. Gjermo P, Rösing CK, Susin C, Oppermann R. Periodontal diseases in Central and South America. Periodontol 2000. 2002;29:70-78. https://doi.org/10.1034/j.16000757.2001.290104.x. PMID: 12102703.

15. Abdellatif HM, Burt BA. An epidemiological investigation into the relative importance of age and oral hygiene status as determinants of periodontitis. J Dent Res. 1987;66(1):13 $-18$ PMID: 3497960. 
16. Solis ACO, Lotufo RFM, Pannuti CM, Brunheiro EC, Marques AH, Lotufo-Neto F. Association of periodontal disease to anxiety and depression symptoms, and psychosocial stress factors. J Clin Periodontol. 2004;31 (8):633-638. https://doi.org/10.1111/j.1600051X.2004.00538.x.

17. Marcenes WS, Sheiham A. The relationship between work stress and oral health status. Soc Sci Med. 1992;35 (12):1511-1520. doi: 10.1016/0277-9536(92)90054-T.

18. Gonzalez YM, De Nardin A, Grossi SG, Machtei EE, Genco RJ, De Nardin E. Serum Cotinine Levels, Smoking, and Periodontal Attachment Loss. J Dent Res. 1996;75 (2):796-802. https:// doi.org/10.1177/00220345960750021001. PMID: 8655777.

19. Palmer RM. Tobacco smoking and oral health. Br Dent J. 1988;164(8):258-260. https://doi.org/10.1038/ sj.bdj.4806420. PMID: 3289594.

20. Moss ME, Beck JD, Kaplan BH, et al. Exploratory CaseControl Analysis of Psychosocial Factors and Adult Periodontitis. J Periodontol. 1996;67(10s):1060-1069. https://doi.org/10.1902/jop.1996.67.10s.1060.

21. Monteiro da Silva AM, Oakley DA, Newman HN, Nohl FS, Lloyd HM. Psychosocial factors and adult onset rapidly progressive periodontitis. J Clin Periodontol. 1996;23 (8):789-794. PMID: 8877667.

22. Chiou L-J, Yang Y-H, Hung H-C, et al. The association of psychosocial factors and smoking with periodontal health in a community population. J Periodontal Res. 2010;45 (1):16-22. 0765.2008.01194.x.

23. Saletu A, Pirker-Fruhauf H, Saletu F, Linzmayer L, Anderer P, Matejka M. Controlled clinical and psychometric studies on the relation between periodontitis and depressive mood. J Clin Periodontol. 2005;32(12):1219 -1225. https://doi.org/10.1111/j.1600-051X.2005.00855.x.

24. Machtei EE, Christersson LA, Grossi SG, Dunford R, Zambon JJ, Genco RJ. Clinical criteria for the definition of established periodontitis. J Periodontol. 1992;63(3):206214. https://doi.org/10.1902/jop.1992.63.3.206.

25. Rabin BS. Stress, immune function, and health: The connection. New York,NY: Wiley-Liss \& Sons Inc;1999.

26. da Silva AM, Newman HN, Oakley DA. Psychosocial factors in inflammatory periodontal diseases. A review. J Clin Periodontol. 1995;22(7):516-526. PMID: 7560234

27. Genco RJ, Ho AW, Kopman J, Grossi SG, Dunford RG, Tedesco LA. Models to Evaluate the Role of Stress in Periodontal Disease. Ann Periodontol. 1998;3(1):288-302. https://doi.org/10.1902/annals.1998.3.1.288. 